\title{
Quantitative and Qualitative in vivo Analysis of Metal Residuals in the Saliva of Subjects with and without Fixed Orthodontic Appliances
}

\author{
G Currò* and G Bilello* \\ Researchers of Department of Surgical, Oncological and Oral Sciences (DiChirOnS), University of Palermo, Italy \\ *Corresponding author: Giuseppa Bilello, Department of Surgical, Oncological and Oral Sciences (DiChirOnS), University of \\ Palermo, Italy \\ Giuseppe Currò, Department of Surgical, Oncological and Oral Sciences (DiChirOnS), University of Palermo, Italy
}

ARTICLE INFO

Received: 蔧 February 19, 2020

Published: February 26, 2020

Citation: G Currò, G Bilello. Quantitative and Qualitative in vivo Analysis of Metal Residuals in the Saliva of Subjects with and without Fixed Orthodontic Appliances. Biomed J Sci \& Tech Res 26(1)-2020. BJSTR. MS.ID.004291.

Keywords: Metal Ions; Fixed Orthodontic Appliances; Saliva; Atomic Absorption Spectrophotometry

\section{ABSTRACT}

Aim of the Work: The aim of this work was to evaluate Ni e Cr ions in the saliva of subjects with and without fixed orthodontic appliances.

Materials and Methods: This was a prospective, non-randomized study of 100 patients, so selected: 50 have undergone fixed orthodontic appliance at least from 24 months; others 50 subjects as control-group, without any fixed and/or removable orthodontic appliance It was conducted according to the Declaration of the World Medical Association of Helsinki. The two selected groups were compatible for age, sex, absence of restoration in amalgam or other metals in the oral cavity. The saliva of all the subjects was collected with standardized sterile methods. The samples were analyzed with an atomic absorption spectrophotometer instrument.

Results: Absolute values of the salivary metal ions in the subjects with fixed orthodontic appliances are more than the values observed in the control group, but these values are within the normal range.

Conclusion: The results show a greater presence in saliva of $\mathrm{Ni}$ and $\mathrm{Cr}$ ions in the group with fixed orthodontic device. This research must be deepened because ions released in saliva can have effects both locally and in distant districts.

\section{Introduction}

Fixed orthodontic appliances including brackets, orthodontic bands and arches are commonly made of stainless steel and nickel titanium. These materials are generally biocompatible, but many studies have shown the possibility releasing nickel ions and some side effects both locally and in distant districts [1-4]. The presence of oxides on the external and internal surface of the metal alloys is responsible for the micro-fissures of the crystal lattice. The corrosion processes can be activated even in depth, making the metal alloy a microporous support that favors the adhesion of the bacterial plaque and through this the process of corrosion can occur even severely, making the metal alloy a microporous support, able to foster the adhesion of bacterial plaque which is then in turn responsible for low $\mathrm{pH}$ values, facilitating the corrosion process through oxides present in the metal [5-8]. In food, in tobacco, as in water, aggressive substances such as chlorides and sulphides can be present, which trigger even marked oxidation phenomena $[9,10]$.

Most fixed orthodontic appliances contain metals of various kinds and in varying quantities. These components are constantly subjected to the action of the salivary fluid, but also undergo the chemical and physical action of food. Various Authors [1,11-17] have stated that the orthodontic appliances released in the oral cavity the ions metals and they create electric currents how due from the difference in electrical potential between the metals immersed in the salivary fluid. The oral environment can conducive to corrosion with release of ions because of the constantly wet mouth environment, constant temperature, and $\mathrm{pH}$ changes in the mouth. Among these ions, nickel has been the subject of major research for its harmful effects on cells, tissues and organs. In 
these studies it has been re-ported that Ni complexes, in the form of arsenides and sulfides, can be allergenic, carcinogenic, and act as mutant substances [18-26]. In fact, $10 \%$ of the population has a hypersensitivity reaction to nickel $[11,13,14,27]$. Some authors have shown that the amounts of nickel released by orthodontic appliances in saliva or serum are significantly lower than the average dietary intake $[27,28]$. The release of ions varies during the different period of orthodontic treatment and depends on the $\mathrm{pH}$ level of the saliva itself. In vitro corrosion studies show different results from the studies conducted in vivo [30-33].

The purpose of the current work is the quantitative and qualitative analysis of the $\mathrm{Ni}$ and $\mathrm{Cr}$ ions released in the saliva in subjects wearing fixed orthodontic appliances. A number of factors influencing the metal releasing are also assessed.

\section{Material and Methods}

Eligible patients for this study were selected from the Department of Orthodontics, University of Palermo. For this study subjects informed consent forms were obtained, and it was conducted ac- cording to the Declaration of the World Medical Association of Helsinki. A total of 100 patients who met the following criteria: studies clinical in vivo, patients aged between 12 and 30, have permanent dentition. All patients must have no amalgam fillings or metal restorations, no previous orthodontic treatment. no previous allergic reaction to Nickel. Excluded were patients with metal restorations, patients with systemic diseases, pharmacological treatment in progress and moreover use of alcohol and smoking. Out of them 50 people were selected to represent the control group without treatment orthodontics. Their age range was from 14 to 22 years (mean 18.5 \pm 3.9 years) The experimental group included 50 (26 females and 24 males) patients with an age range from 16 to 19 years (mean 17.5 \pm 2.9 years). were healthy orthodontic patients with fixed appliances. The fixed appliances consisted of an average of 4 stainless orthodontic bands and 20 bonded stainless-steel brackets (3 M UniteK, California USA, 0,022-inch slot). The archwires used were all in stainless steel. The patients underwent salivary sampling in the range 16-18 months after the start of treatment with fixed orthodontic appliances experiment .

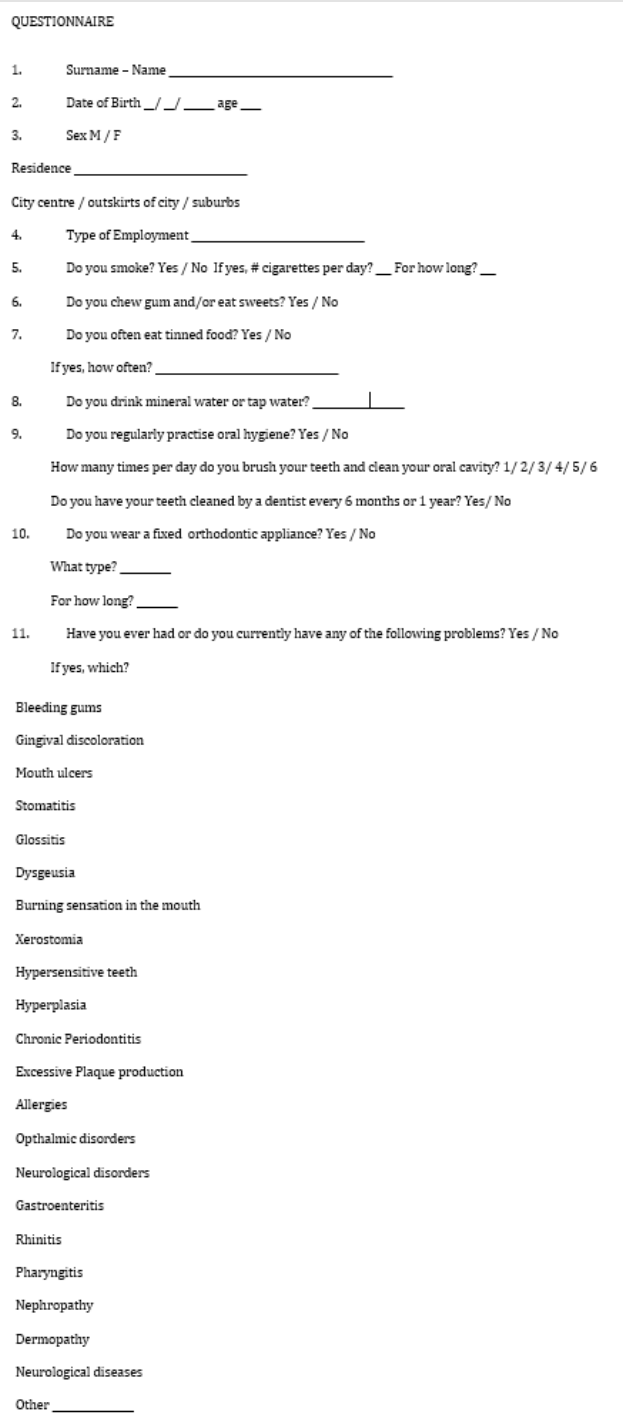

Figure 1: Questionnaire administered to all patients. 
The metal content determinations were carried out using atomic absorption spectrophotometry with a graphite furnace. We have proceeded, for all patients to the administration of a questionnaire (Figure 1), introduced anonymously, on the habits of life (oral hygiene, smoking, nutrition, etc.) in order to also assess the presence of any pathologies, disorders oral or systemic, among those that in the literature are more indicated as related to the release of metal ions. Later the patients of both groups performed the same standard procedure. All patients were instructed to avoid rinsing and eating at least 30 minutes before sampling. Sample collection was carried out such that after rinsing with $20 \mathrm{ml}$ of distilled water for 45 seconds. Then unstimulated saliva sample was collected, from each subject, in sterile $50 \mathrm{ml}$ propylene tubes (Figure 2). The saliva withdrawal was always carried out by the same operator. The samples thus collected were collected inside the test tubes, sent to the laboratory where they were then investigated using a "SIMAA 6000" PERKIN - ELMER atomic absorption spectrophotometer to search for traces of $\mathrm{Cr}$, Ni metals. With this technique there was not necessity separating the metal from its biological matrix. The results were considered as nanograms for milliliter. All the data thus obtained were processed using Microsoft (C) Excel (C) worksheets .

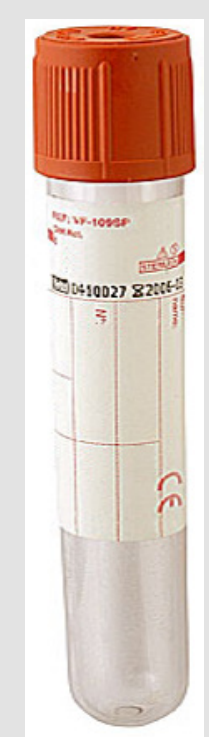

Figure 2: Sterile $50 \mathrm{ml}$ propylene tubes.

\section{Results}

The quantitative values of the $\mathrm{Ni}$ and $\mathrm{Cr}$ metals expressed in $\mu \mathrm{g} / \mathrm{l}$, searched in the two groups of subjects are presented in the Graphs $1 \& 2$. In this research, the values of metal ions, to be considered normal, refer to the work of Prof. P. Apostolie coll., University of Brescia. The Ni values are presented in Graph 1, divided into lower and upper part. The lower part (yellow) has normal $\mathrm{Ni}$ levels, values between 0 and $5 \mu \mathrm{g} / \mathrm{l}$ are also compared to the data of the two groups observed. The Ni values over $5 \mu \mathrm{g}$ / l (orange area) are to be considered outside the normal range. As can be seen from the graph, the Ni values of subjects with fixed orthodontic appliances (in green) are higher than control subjects (in orange). In particular, 4 subjects exceed the limit value of $5 \mu \mathrm{g} /$ l while other 6 remain just below this threshold of a few $\mu$ g. Among the control subjects, however, there are no particularly high values, and no one exceeds the limit value of $5 \mu \mathrm{g} / \mathrm{l}$

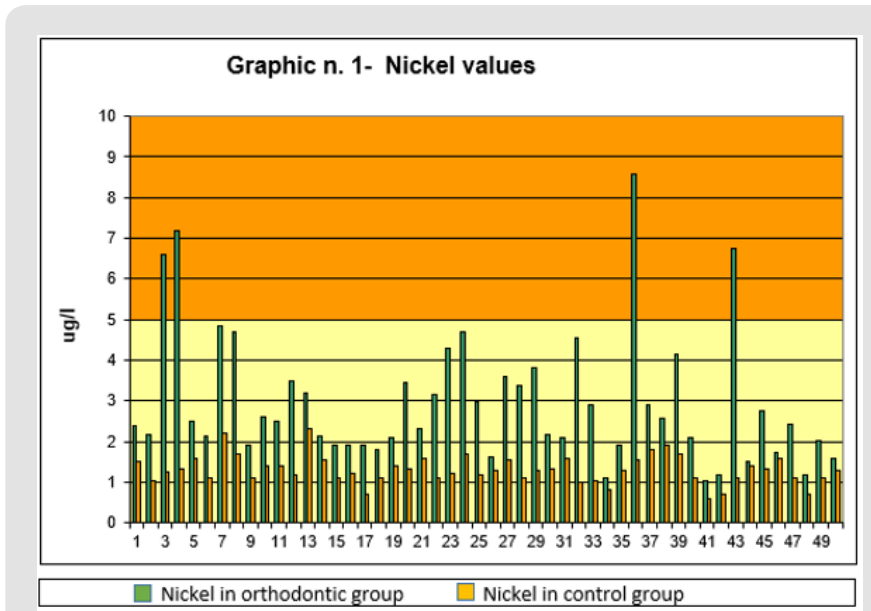

Graph 1: Shows the average values of the Nickel ions, in the group with fixed appliance and in the control group.

As for the $\mathrm{Cr}$ values, they are presented in Graph 2. The lower area of the graph, starting from the value of $3 \mu \mathrm{g} / \mathrm{l}$, has a different color than the upper part. The value of $\mathrm{Cr}$ (zone in yellow) between 0 and $3 \mu \mathrm{g} / \mathrm{l}$, is to be considered normal. The values of $\mathrm{Cr}$ above 3 $\mu \mathrm{g} / \mathrm{l}$ (orange area) of the upper part are to be considered outside the normal range. As can be seen from the graph, the $\mathrm{Cr}$ values of the subjects with fixed orthodontic appliances (in red) are higher than control subjects. In particular, among subjects with fixed orthodontic appliances 4 exceed the limit value of $3 \mu \mathrm{g} / \mathrm{l}$ while other 6 remain just below this threshold of a few $\mu$ g. Among the control subjects, there are no particularly high values and all within normal limits.

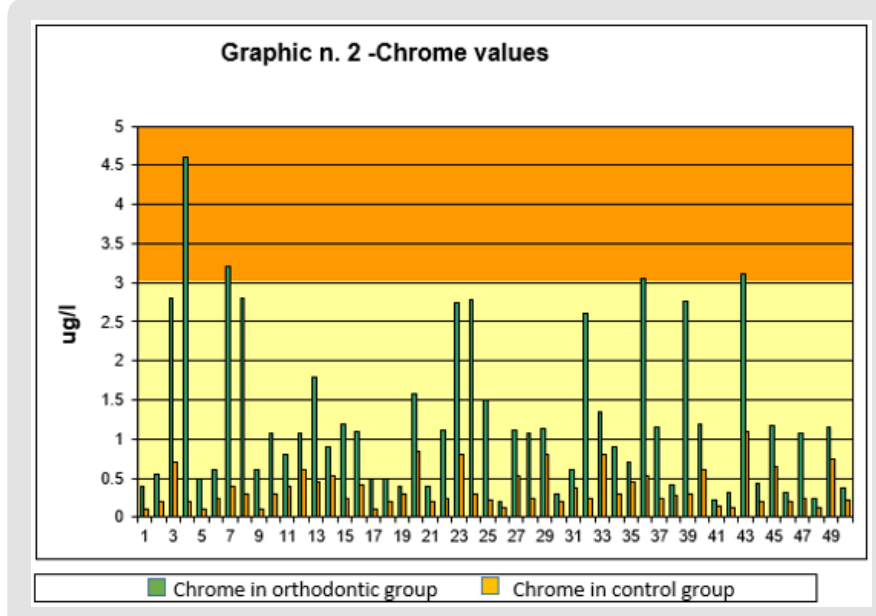

Graph 2: Shows the average values of the Chrome ions, in the group with fixed appliance and in the control group.

\section{Discussion}

The fixed orthodontic appliance, used in this work are made with stainless steel. This appliance can release metal ions into 
the oral cavity for due to corrosion. The results show a greater presence of $\mathrm{Ni}$ and $\mathrm{Cr}$, expressed in $\mu \mathrm{g} / \mathrm{l}$, in the salivary of the group with fixed devices compared to the control group. Corrosion is an electrochemical phenomenon and the types of corrosion observed in the oral cavity are in the category of wet corrosion. Some variables can interact with these data, such as the metal traces found in commonly used objects, particular lifestyle habits and environmental sources. For this reason it is necessary to carry out further research on the factors that could affect the level and values of these metals in the oral cavity. Corrosion causes release of metal ions to the saliva when the PH is lowered in the oral cavity (values around 3.5) . Corrosion depends mainly on these factors:

a) Metallurgical characteristics of the alloys used for fixed orthodontic appliances.

b) Subjective factors, such as saliva composition and salivary flow, eating habits, smoking, oral hygiene, etc.

c) The mechanical stress that triggers stress corrosion.

d) The oxygen tension that varies between exposed and internal areas of the devices [28].

Therefore, the oral environment being a galvanic cell, the metals of orthodontic appliances create potential differences in the mouth from 200 up to 1000 milliVolts, going to corrosion. The same microorganisms interacting with the metal surfaces, they also create variations in oxygen tension, $\mathrm{pH}$ and local chemistry, contributing to the metallic alteration The combination of these chemical and physical phenomena involves the passage of weak currents in the tissues with dispersion in the oral cavity and in the tissues of metal ions [34]. Cellular and tissue metabolism, both local and systemic, also influences the onset and progression of corrosion phenomena.

\section{Conclusion}

The study is conducted on patients with fixed orthodontic appliances therapy compared with patients without orthodontic appliance. The results show to increased levels of $\mathrm{Ni}$ and $\mathrm{Cr}$ ions in the saliva of patients in therapy. we can find this ions also in soft tissues, and even organs.

\section{Author Contributions}

All authors listed, have made substantial, direct and intellectual contribution to the work, and approved it for publication.

\section{Conflict of Interest}

The authors declare that the research was conducted in the absence of any commercial or financial relationships that could be construed as a potential conflict of interest.

\section{References}

1. Amini F, Borzabadi Farahani A, Jafari A, Rabbani M (2008) In vivo study of metal content of oral mucosa cells in patients with and without fixed orthodontic appliances. Orthod Craniofac Res 11(1): 51-56.
2. Amini F, Jafari A, Amini P, Sepehr Sepasi (2012) Metal ion release from fixed orthodontic appliances- an in vivo study. Europian Journal of Orthodontics 34(1): 126-130.

3. Eliades T, Zinelis S, Papadopulos MA, Eliades G, Athanasiou AE (2004) Nickel content of as received and retrieved NiTi and steinless steel arch wires: assessing the Nickel release hypothesis. Angle Orthodontist 74( 2) 151-154.

4. Eliades T, Bouraouel C (2005) Intraoral aging of orthodontic material: the picture we miss and its clinical relevance. Am J Orthod and Dent Orthop 127(4): 403-412.

5. House K, Sernetz F, Dymock D, Sandy JR, Ireland AJ (2008) Corrosion of orthodontic appliances- should we care? Am J Orthod Dentofacial Orthop 133(4): 584-592.

6. Imani MM, Mozaffari H R, Ramezani M, Sadeghi M (2019) Effect of fixed orthodontictreatment on salivary nichel and chromium levels: a system review and meta-analysis of observational studies. DEnt J 7(1).

7. Golz L, Knickenberg A, Keilig, Reimann S, Papageorgiou SN (2016) Nichel ion concentrations in the saliva of patients treated with self-ligating fixed appliances: a prospective cohort study. J Orafacial Orthopedics 77(2): 85-93.

8. Bayramoğlu G, Alemdaroğlu T, Kedici S, Aksüt AA (2000) The effect of $\mathrm{pH}$ on the corrosion of dental metal alloys. J Oral Rehab 27(7): 563-575.

9. Eliades T, Athanasiou AE (2002) In vivo aging of orthodontic alloys: implications for corrosion potential, nickel release and biocompatibility. Angle Orthod 72(3): 222-237.

10. Cheung Chung SW, Kwong KP, Yau JCW, Wong WWK (2008) Dietary exposure to antimony, lead and mercury of secondary school students in Hong Kong. Food Addit Contam 25(7): 831-840.

11. Prakash P, Rath S, Mukherjee M, Malik A, Boruah D, et al. (2014) Comparative evaluation of the marginal gingival epithelium in smokers and nonsmokers: a histomorphometric and immunohistochemical study. Int J Period Rest Dent 34 (6): 781-786.

12. Gjerdet NR, Erichsen ES, Remlo HE, Evjen G (1991) Nickel and iron in saliva of patients with fixed orthodontic appliances. Acta Odont Scand 49(2): 73-78.

13. Kerosuo H, Moe G, Hensten Pettersen A (1997) Salivary Nickel and Chromium in subjects with different types of fixed orthodontic appliances. Am J Orthod Dentofacial Orthop 111(6): 595-598.

14. Kocadereli L, Atac PA, Kale PS, Ozer D (2000) Salivary Nickel and Chromium in subjects with fixed orthodontic appliances. Angle Orthod 70(6): 431-434.

15. Ağaoğlu G, Arun T, Izgi B, Arat A (2001) Nickel and Chromium levels in the saliva and serum of patients with fixed orthodontic appliances. Angle Orthod 71(5): 375-379.

16. Fors R, Persson M (2006) Nickel in dental plaque and saliva and serum in patients with and without orthodontic appliances. Eur J of Orthod 28(3): 292-297.

17. Levrini L, Lusvardi G, Gentile D (2006) Nickel ions release in patients with fixed orthodontic appliances. Min Stomatol 55(3): 115-121.

18. Singh DP, Seghal V, Pradhan KL, Chandna A, Gupta R (2008) Estimation of nickel and chromium in saliva of patients with fixed orthodontic appliances. World J of Orthod 9(3): 196-202.

19. Costa M, Salnikow K, Cosentino S, Klein CB, Huang X, et al. (1994) Molecolar mechanisms of nickel carcinogenesis. Envir Health Persp 102(3): 127-130.

20. Zhou D, Salnikow K, Costa M (1998) Cap43 A novel gene specifically induced $\mathrm{Ni}^{2+}$ compounds. Cancer Res 58(10): 2182-2189.

21. Oller AR, Costa M, Oberdorster G (1997) Carcinogenicity assessment of selected nickel compounds. Toxicol and Appl Pharmacol 143(1): 152166. 
22. Novelli ELB, Hernandes RT, Novelli Filho JLVB, Barbosa LL (1998) Differential/combined effect of water contamination with cadmium and nickel on tissues of rats. Envir Poll 103(2/3): 295-300.

23. Wataha JC, Lockwood PE, Marek M, Ghazi M (1999) Ability of nickelcontaining biomedical alloys to activate monocytes and endothelial cells in vitro. J of Biom Mat Res 45(3): 251-257.

24. Dayan AD, Paine AJ (2001) Mechanism of chromium toxicity, carcinogenicity and allergenicity: review of the literature from 1985 to 2000. Human and Experim Toxicol 20(9): 439-451.

25. Burgaz S, Demircigil GC, Yilmazer M, Ertas N, Kemaloglu Y, et al. (2002) Assessment of cytogenetic damage in lymphocytes and in exfoliated nasal cells of dental laboratory technicians exposed to chromium, cobalt and nickel. Mutant Res 521(1-2): 47-56.

26. Genelhu M C, Marigo M, Alves-Oliveira LF, Malaquias LC, Gomez RS, et al. (2005) Characterization of nickel-induced allergic contact stomatitis associated with fixed orthodontic appliances. Am J Orthod Dentof Orthop 128(3): 378-381.

27. Currò G, Bilello G (2016) Experimental analysis of the metal ions present in the saliva of subjects with mobile orthodontic appliances. 12(4): 1011

\section{ISSN: 2574-1241}

DOI: 10.26717/BJSTR.2020.26.004291

\section{G Currò, G Bilello. Biomed J Sci \& Tech Res}

This work is licensed under Creative Commons Attribution 4.0 License

Submission Link: https://biomedres.us/submit-manuscript.php
28. Huang H, Chiu Y, Lee T, Wu SC, Yang HW, et al. (2003) Ion release from $\mathrm{NiTi}$ orthodontic wires in artificial saliva with various acidities. Biomat 24(20): 3585-3592.

29. Kutha M, Pavlin D, Slaj M, Varga S, Lapter Varga M, et al. (2009) Type of archwire and level of acidity: effects on the release of metal ions from orthodontic appliances. Angle Orthod 79(1): 102-110.

30. Park HY, Shearer TR (1983) In vitro release of nickel and Chromium from different types of simulated orthodontic appliances. Angle Orthod 84(2): 156-159.

31. Hwang CJ, Shin JS, Cha JY (2001) Metal release from simulated fixed orthodontic appliances. Am J Orth Dentof Orthop 120(4): 383-391.

32. Luft S, Keilig R, Jager A, Bourauel C (2009) In vitro evaluation of the corrosion behaviour of orthodontic brackets. Orthod Craniof Res 12(1): 43-51.

33. Mockers O, Deroze D, Camps J (2002) Citotoxicity of orthodontics bands, brackets and archwires in vitro. Dent Mater 18(4): 311-317.

34. Petoumenou E, Amdt M, Keilig L, Reimann S, Hoederath H, et al. (2009) Nickel concentration in the saliva of patients with nickel-titanium orthodontic appliances. Am J Orthod Dentof Orthop 135(1): 59-65.

$\begin{array}{ll}\text { BIOMEDICAL } & \text { Assets of Publishing with us } \\ \text { RESEARCHES } & \text { - Global archiving of articles } \\ \text { - Immediate, unrestricted online access }\end{array}$

